\title{
A Comprehensive Overview of Home Telehealth
}

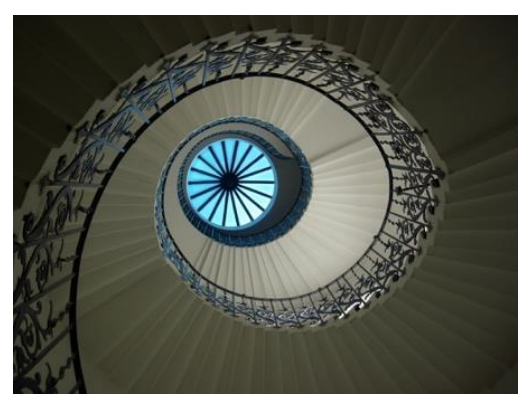

Thomas F. Osborne, MD

Bryan T. Arkwright, MHA

Joel J. Reich, MD, FACEP

John Russo, Jr, PharmD

Editor's note: The article here is reprinted from Dr. Osborne's chapter in, Chau, Diane and Thomas Osborne (eds.) (2017) Application of Technology to the Care of the Older Adult. New York: Springer Publishing Company, with permission.

Treating illness at home is a tradition that has recently been revitalized by a number of factors. Specifically, telecommunication tools, financial imperatives, quality initiatives, staffing constraints, and patient preference are among the leading drivers for this transition. Successful telehealth program outcomes depend on a number of issues, with knowledge, leadership, and management being paramount. Technological advancements and adoption of new care models will change the way we practice medicine and facilitate the effective transition to homecare in select populations.

\section{Historical perspective}

Up until the early 19 th century, the United States economy was primarily agricultural. In this often expansive rural landscape, most healthcare was provided by a household member, who was sometimes relegated to the role of fulltime caregiver. Although there 
were limited institutions for the sick in urban areas during this time period, they were primarily intended for the marginalized and poor.

Medical scientific advancement, development of professional standards, and improved facility conditions, enhanced the credibility of hospitals which dramatically grew in number from 120 hospitals in 1873 to 4,300 in $1909 .{ }^{1-6}$ Amid this growing popularity of hospital based care, the 'house call' remained a dominant factor for a short period, accounting for $40 \%$ of encounters in 1930 , but falling rapidly to $10 \%$ in 1950 s, and reaching less than $1 \%$ of older patients in the 1990 s. $^{7}$

\section{Cost pressures}

The unsustainable increasing costs of hospital-based care has prompted numerous federal policy changes, often mirrored by private insurers. For example, in 1983 Medicare dramatically changed reimbursement policy with a newly implemented payment system of 'diagnosis-related groups' which reimburses hospitals based on the expected complexity of care and not number of days. This historic change has incentivized hospitals to discharge patients as soon as possible. ${ }^{8}$ However, discharging a patient too early can result in costly readmissions and unnecessary and potentially life threatening complications. This had led to the development of transitional care options. However, the costs for subacute care centers and long-term healthcare options outside of the hospital are also high, with recent U.S. estimates ranging between $\$ 210.9$ billion $^{9}$ and $\$ 317.1$ billion annually. ${ }^{10}$ Of further concern, the number of people utilizing these types of services is projected to dramatically increase from 15 million in the year 2000 to 27 million in the year 2050. ${ }^{11}$

Therefore, this extraordinary financial burden is a major concern for all stakeholders, ${ }^{12-}$ 14 and as a result, efficiently caring for these patients has become an increasingly important topic in healthcare reform and policy. ${ }^{15-18} \mathrm{Home}$ telehealth programs offer an appealing alternative or extension to acute care services and acute, subacute, and longterm care centers or nursing home facilities. With appropriate discharge planning and coordinated follow up, effective home health programs are intended to reduce the 
likelihood of hospital readmission. Even though telehealth programs have the potential to dramatically reduce cost, lagging federal reimbursement policies are a barrier to implementation.

\section{Shift back to home healthcare}

There are additional overarching benefits which are driving the shift back toward homebased care. From a clinical perspective, providing care in a patient's own residence reduces the risk of acquiring nosocomial infections, which may be antibiotic resistant. In addition, there are patients with clinical conditions ranging from Alzheimer's disease to autism, who may be more effectively treated in the home. Geographic disparities that would otherwise limit access to specialist may also be eliminated and thereby make healthcare more equitable. ${ }^{8}$ Virtual visits also improve access to basic care by overcoming transportation constraints which may otherwise limit the ability for patients to participate in routine follow-up. In addition, wellness programs and preventive measures may be more accessible and utilized to a greater extent if made available in the home. Importantly, a digitally connected home can empower independence and promote a sense of security. It is therefore not surprising that there is a growing desire among many consumers to shift their healthcare to the familiar comfort and convenience of their own residence. ${ }^{17-19}$

\section{Spectrum of home health patients}

Currently, the majority of home health services address the chronic needs of older patients. ${ }^{20-22}$ The majority of diseases encountered in this setting parallel prevalence in the geriatric population, with home telehealth services for diabetes, hypertension, heart disease, stroke, cancer, arthritis, COPD, atrial fibrillation, dementia, and depression encountered at the highest frequency. ${ }^{23}$

Although elderly long-term care is projected to be a major focus for home health services, the same basic concepts and infrastructure may be transferrable to different and/or overlapping patient populations. To this end, numerous programs are being 
developed for other health needs ranging from urgent care, pediatrics, rehabilitation medicine, post-surgical follow-up, and general wellness. ${ }^{24-26}$

\section{Technological advances}

Fortunately, recent technological advances in miniature sensors, low-power integrated circuits, wireless communications, and broadband data network availability have enabled the development of low-cost mobile health data gathering tools that can efficiently monitor many specific illnesses. ${ }^{27,28}$

In addition to technological solutions designed for individual diseases, there is also a growing need to manage more complex patients with multiple illnesses. ${ }^{29}$ In this situation, it is not uncommon for patients to have several caregivers to address a variety of ailments and comorbidities. Unfortunately, when there are different specialists working in isolation, an unintended consequence may be uncoordinated care that can lead to life-threating problems such as inappropriate polypharmacy, the incidence of which is high in older home health patients. ${ }^{30-33}$ This challenge underscores the need for an integrated and interoperable enterprise health information platform that connects caregivers and facilities to help prevent medical errors.

\section{Providing value and the Triple Aim}

Healthcare providers are being asked to do more with the same or decreased funding and resources. Many health professions (e.g., primary care providers, nurses, and advanced practice professionals) are also projected to have major shortages in staffing which, if not augmented by technological advancement, will result in poorer patient outcomes. ${ }^{34-37}$ At the same time, patients and payors are looking for greater value in both outcomes and overall experience.

In response to these pressures the U.S. healthcare system is undergoing unprecedented transformation. Payment reform is moving from fee-for-service to valuebased reimbursement and technological advancements combined with operational 
changes are facilitating a transition from intensive institutional care settings such as the hospital to less formal settings including the home. ${ }^{38}$

Creating effective, less costly, patient-centered alternatives requires a redesign of many fundamental aspects of healthcare delivery. Home telehealth programs hold great promise in facilitating this critical paradigm shift in healthcare. Success depends on interrelated factors, which are well illustrated in the context of the Triple Aim.

\section{The Triple Aim}

The "Triple Aim" is a framework developed for improved population health. This ambitious strategy was developed by the Institute for Healthcare Improvement $(\mathrm{IHI})$ a decade ago in its effort to redesign the U.S. healthcare system. As stated by Dr. Donald Berwick, the former President \& CEO of IHI, “... the United States will not achieve highvalue healthcare unless improvement initiatives pursue a broader system of linked goals. In the aggregate, we call those goals the "Triple Aim": improving the individual experience of care; improving the health of populations; and reducing the per capita costs of care for populations." 39

Triple Aim implementation began in 2007 with a group of 15 organizations in the U.S., England, and Sweden and was quickly adopted by The Centers for Medicare and Medicaid Services (CMS) during Berwick's short tenure as Administrator. The goals have subsequently become the "mantra" of healthcare reform, with adoption of the aims by many healthcare systems and accountable care organizations. As a result, in 2014, more than 150 organizations across the world participated in efforts to achieve these aims. ${ }^{40}$

In recognition of the high degree of interdependence, the intent of the Triple Aim is to achieve the three linked goals simultaneously. However, the synchronized achievement of these interrelated measures is complex and challenging. The required redesign of healthcare financial, clinical, and operational relationships underscores that these goals will not be achieved with minor modifications to the status quo. However, for 
simplification of discussion, the following sections will consider each component of the Triple Aim individually in relation to how it relates to home telehealth.

\section{Improving the individual experience of care}

Home telehealth may improve the experience of care in various ways. For many, the familiar comfort and convenience of one's own home is much more appealing than a healthcare facility and therefore it is not surprising that there is a growing vocal trend among seniors and baby boomer, soon-to-be seniors, who prefer this option. ${ }^{41,42,43}$ Home healthcare services are essential for those who are homebound and are of great value to those for whom the logistics of traveling to a provider's office is a tremendous burden. In addition, due to frailty or functional limitation, many would benefit from the added safety of digital monitoring in the home or in non-medical residential institutions such as assisted living facilities. As a result, a technology-enabled home health system can prolong independence and one's control of the context.

User acceptance is a foundational component to achieving a positive home telehealth care experience and begins with selecting appropriate patients who are comfortable using the specific technology. ${ }^{44}$ The. technology components of home telehealth, including glucometers, oximeters, and digital scales, have been available for many years as standalone devices. Historically, data collection and reporting has for the most part been manual, often in the form of patient-generated handwritten records, which are then carried to the care provider at the time of office visits. Advances in wireless device technology, increased accessibility to broadband networks, and integration, have significantly advanced the capability to report, aggregate, and share the biometric data with care provider teams to enable timely data analysis and response times.

Acceptance and endorsement from members of the care team is a sometimes neglected but critical step for success. ${ }^{45}$ On a similar note, engagement of appropriately designated family and friends is also a key factor for an improved healthcare experience. This is particularly true for friends and family of patients who are chronically ill, disabled, or elderly because they are likely to be involved in each stage of home 
telehealth implementation. Therefore, measures to incorporate all of these collaborators in the enrollment, setup, management, and troubleshooting of home telehealth solutions should not be overlooked. Failure to properly address each of these stakeholders may result in dissatisfaction and the perception that technology has become a substitute rather than an enhancer of the team relationship. ${ }^{46}$

Improved acceptance and experience from each collaborator can be achieved with a thoughtful approach to the overall design of the program and selection of the appropriate technological tools. However, balancing a technology's utility with usability can be challenging. ${ }^{47}$ For example, design considerations for older patients should include providing tools and interfaces that take into account common issues such as potential vision, cognitive, and dexterity limitations, as well as inexperience with digital technology.

Special care and attention must also be given to the workflow and needs of care providers. Home telehealth functions best when it is integrated into the established care process and information systems. ${ }^{48}$ Regrettably, many home telehealth programs are free-standing and not interoperable with health system EHRs (electronic health records) and population health database tools, which is a significant impairment to success. If the home telehealth program becomes intrusive due to poorly designed technology or workflow, the resulting decreased provider efficiency will make it virtually impossible to obtain the necessary support and participation for effective adoption. When technological tools are developed without the direct consultation or understanding of a healthcare provider's perspectives, the results are typically suboptimal. For example, a well-intended tool may have negative consequences such as overly aggressive alert thresholds resulting in disruptive false alarms that consume valuable time when staff responds to a non-event, or, at the other extreme, delayed (or nonexistent) response, with the potential for negative outcomes due to real events missed. With either scenario, cost of care increases without obvious purpose. ${ }^{49}$ Similarly, a primary care physician may derive considerable value from an organized once per month summary of glucose measurements, however, delivery of daily or hourly noncritical results may quickly lead 
to frustration. As with all other health information technology systems, privacy, data security, interoperability, data aggregation, and technical support are essential for sustainability.

Home telehealth also has the potential to significantly enhance the experience of care through both healthcare provider and social connections. These benefits include, but are not limited to, creating a direct connection to care providers, friends, and family as well as providing a sense of security via appropriate electronic safety alerts. The potential benefits of dampening the social isolation experienced by many who are chronically ill, as well as empowerment of self-management and independence should not be understated. The overall improved home healthcare experiences that can be achieved in these situations is reflected in the high patient satisfaction scores reported by patients participating in these programs within the Veterans Health Administration system and others. ${ }^{45,46,50}$

\section{Improving the Health of Populations}

The ultimate goal of population health is to define the population's health needs and disparities, identify the individuals who have these needs, and address the needs through care management and coordination and clinical services.

While there are many methodologies for defining populations and data, ultimately patients are stratified into groups to enable the most beneficial assignment of resources to define, track, and manage needs. Depending on the perspectives, populations may be defined by criteria such as disease type, severity scoring, source of payment, and geography. Patient stratification, often illustrated with a pyramid, is used to illustrate progressively more intense care services required; beginning at the low risk group that is well-served by wellness programs, the moderate risk group with coaching and selfcare/management, high risk group with disease management, and the very high risk group with the addition of case management. Individuals with one or more chronic diseases in the moderate risk group, high risk group and noninstitutionalized very high risk group derive the greatest clinical value from home telehealth. ${ }^{51}$ 
Research from the past decade has shown mixed results regarding the value, return-oninvestment, and efficacy of home telehealth programs. There are many variables to consider and therefore these studies need to be thoughtfully evaluated in the context of the specific program, patient population, and methodology. An additional challenge in the evaluation of home telehealth programs is applying research findings from studies of a single disease entity to patients in the high and moderate severity population who often have multiple diseases. As a result, the limited scope of many research studies leaves unanswered questions regarding the full potential of home telehealth for more complex patients. ${ }^{52}$

Meaningful evaluation is also confounded by the difficulty in obtaining complete followup data when multiple sites of care (hospitals, physician offices, labs) are utilized in unrelated health systems without interoperable data systems. ${ }^{8}$ Therefore, critical considerations include factors such as the degree of network development, leadership, care provider support for home telehealth, and the extent of clinical integration at the time of the study. ${ }^{53,54}$ It is becoming clear that a successful home telehealth program needs to be well-integrated into a system, which includes linked home health, disease management, transitional care, and primary care services. ${ }^{11}$ Without these components and a well-constructed response plan, its full value will not be realized. ${ }^{8}$ By example, favorable results for home telehealth have been reported by well-organized integrated programs such as the Veterans Health Administration, Banner Health, and Geisinger Health System. ${ }^{45,55,56}$

\section{Reducing per capita costs of care for populations}

Staggering healthcare costs across virtually all patient populations have far reaching implications to our economy and society. In response to this, government payors (i.e., Medicare and Medicaid) and commercial insurance companies (including employer selffunded health insurance) are shifting financial risk to healthcare systems and physicians through shared savings, bundled payment, and capitation programs. There are many variations in these plans; however, they all share the common goal of replacing more 
expensive care with improved primary care, care management and coordination, preventive medicine, as well as other safe alternatives. ${ }^{57}$

The goal of efficiently lowering healthcare costs is particularly important for our growing senior population, who are living longer with multiple chronic conditions, functional impairment, frailty and social stressors. This dilemma is especially problematic because this population already accounts for half of the costliest $5 \%$ of patients. ${ }^{58}$ Multiple federal cost saving measures are being initiated to meet this challenge. While there are many views on how to most effectively reduce healthcare spending, considerable effort is presently focused on reducing acute hospital care and home telehealth is well positioned to be an important part of the solution.

In addition, CMS rating programs, as well as those implemented by private insurance companies, use readmission as a key metric for determining rewards and penalties. This has become increasingly important because with shortened hospitalization, patients, particularly the elderly, may leave the hospital before being completely stable and without a thorough understanding of diet, medication and follow-up discharge instructions. In addition, these patients are also more vulnerable and in greater need of support to make the care transition safer and to avoid readmission. ${ }^{59}$ When combined with organized residential safety assessments, a specifically designed and technologically enabled, home telehealth program can bridge this critical gap. When successfully implemented, a well-integrated system can identify early status changes for the conditions contributing the most to hospitalization and re-hospitalization such as heart failure, COPD/pneumonia, diabetes and the myriad complications of diabetes. A common example is weight gain by a heart failure patient. Early identification of the change in status can lead to timely intervention and management at home or at the primary care physician's office, therefore avoiding an expensive emergency department and/or hospital admission. ${ }^{60}$

In our dynamically changing reimbursement system calculating exactly where the cost savings occur, and to whom they accrue is challenging. In the traditional fee-for-service 
system, reduced hospital admissions decrease a health system's revenue and therefore this lack of alignment has been a source of federal policy changes. On the other hand, in a physician-only shared savings program, a physician group may be financially rewarded for reducing hospital admissions. Likewise, the cost to the insurer is also reduced when hospital admissions is avoided.

In a value-based system with risk-sharing, the expense to create the infrastructure that results in the savings may occur in different areas of the network. For example, a home health provider may run the home telehealth program with payment from direct monthly fees or a grant, yet the savings on reduced expenses such as acute hospitalizations may benefit a local independent Accountable Care Organization or clinically integrated network. ${ }^{48,51,61}$ Similarly, remote management of chronic diseases in partnership with a primary care provider may also reduce expenditures for specialist care and lab testing. Furthermore, preventive care measures provided electronically in the home, including wellness education and activity monitoring via wearable technology, may result in cost savings to multiple different entities.

While system level cost reduction efforts have considerable importance, those accrued to individuals, families, and groups that compose the populations is a critical component of system transformation's success or failure. It is difficult to place a dollar value on improved personal health and quality of life; however, there are some variables that can be calculated directly, including fewer absences from work, reduced out-of-pocket expenditures on emergency department and acute hospitalization costs, as well as the associated transportation costs.

As part of an effort to increase value, in both the fee-for-service system and the valuebased payment systems, CMS and private insurance programs allocate both direct financial rewards and penalties based on patient experience scores. Poor patient and family experience also places considerable fee-for-service revenue at risk due to damaged institutional reputation and decreased referral rates. Because a successfully implemented home telehealth program contributes positively to patient and family 
experience, it therefore results in financial benefit to the care provider in many ways regardless of the payment model.

As value-based payment and accountable care arrangements mature and grow, the true benefits of home telehealth may be more fully realized. Overall, however, attainment of the Triple Aim may require substantial reallocation of healthcare resources from traditional fee-for-service payment arrangements to clinically integrated "valuebased" payment models.

\section{Objective insight}

Although the promise of telehealth may seem intuitively obvious, there is also a critical need to continually and objectively evaluate assumptions. For example, a recent analysis reviewed 36 journal articles and found telehealth to be more expensive in $31 \%$ of cases. Importantly, the article authors suggested that the specific organizational model employed in the delivery of care was more important to the success of the program than the type of technology utilized. ${ }^{62}$ In a separate study, the authors suggested that the lack of an effective infrastructure for case management was the pivotal factor in the lack of reportable benefit to telehealth monitoring. ${ }^{15}$ These examples underscore that technology by itself is not effective. Tools need to be evaluated, tested and implemented with an understanding of existing requirements and workflows with the primary goal of quality patient-centered care. In the words of Jeffrey K. Liker, "Use only reliable, thoroughly tested technology that serves your people and processes". ${ }^{63}$

\section{Leadership and management}

The skills of leadership and management are critically important to success because it can take as much time, effort, and resources to implement the right solution as it does to create the wrong one. To this end, the required interplay between change and order are dependent on a number of complementary factors including clear communication, vision, empowerment, strategy, alignment, and a deep understanding of the national and local healthcare environment, as well as thoughtful evaluation, planning, requirements gathering, structure, and stakeholder involvement. ${ }^{63-66}$ 
Specific considerations such as potential technical limitations in broadband internet connectivity, interoperability with information systems, the need for uniform standards between electronic health records, cost, relevance of the proposed solutions, reliability, user acceptance, as well as legal, ethical and facility-organizational factors need to be addressed. Understanding these types of variables and requirements will reveal valuable information about the most successful path to implementation as well as the projected benefits and impacts. ${ }^{67}$

Planning for long-term maintenance and continual improvements based on open feedback and ongoing evaluation are also key factors to long-term achievement and sustainability. ${ }^{68,69}$

The success of any telehealth program depends on user acceptance. In the case of technologically-enabled home healthcare, the end-users are varied and include patients, caregivers, support staff, and administrators. ${ }^{70}$ To be successful, the solutions must meet the needs of each major stakeholder. Thoughtfully designed user interfaces tailored to the specific audience promote an effective, intuitive, and enjoyable experience, which also decreases the need for training and elaborate change management strategies. Tools should improve upon an existing framework and not produce an environment where people become subservient to technology. ${ }^{63}$

These issues are particularly pertinent to home caregivers who may already be overworked; home health nurses work more hours than nurses in nearly any other setting..$^{71}$ Importantly, it has been shown that improved managerial support of nursing practice and better relations with physicians, can translate to improved morale and patient outcomes. ${ }^{72,73}$ Therefore, technological communication tools that bridge these gaps may also provide nonlinear paths to improved patient care.

\section{Operational challenges of telehealth}


The intrinsic geographically isolated nature of home healthcare requires advanced tools for the coordinated collaboration of patients, cross-functional teams, tools, and disciplines. To this end, a successfully implemented technological infrastructure is required to provide a platform for efficient communication and engagement for everyone involved.

Therefore, the availability and reliability of internet connections is a potential critical limitation to the deployment of specific solutions such as synchronous videoconferencing and biometrics tracking. ${ }^{74,75}$ Nonetheless, in situations of limited internet access, a less desirable delayed information transfer to caregivers can still be achieved asynchronously in a "store-and-forward" process.

The connected benefits of telehealth also come with concerns regarding the security of protected health information that will be digitally transferred to offsite caregivers. ${ }^{76-78} \mathrm{In}$ addition, the various patient health metrics obtained will need to be presented to caregivers in an efficient, user-friendly format. ${ }^{79,80}$

Even with the most robust technical infrastructure, periodic in-person home visits by a caregiver are often part of a complete home health solution. However, the unstandardized home environment presents efficiency and safety challenges to visiting healthcare examiners and these issues also need to be systematically addressed. ${ }^{75} \mathrm{In}$ addition, the use of relatively low tech options such as railings, adjustable shower seats, and motion activated lights provide important levels of added patient safety and independence that should not be overlooked.

\section{Future technology directions}

Iterative improvements of existing technological solutions will drive greater value and user acceptance to this disruptive home care model. However, new developments in the fields of machine learning, artificial intelligence, analytics, integrated networks, and robotics will drive a paradigm shift in how we practice medicine. 


\section{Conclusion}

A number of interdependent factors have made home healthcare an attractive option for many. Leadership, management and technology are among key factors for success. Home telehealth programs not only hold the potential to solve an escalating demand at a lower cost, but also may achieve that goal with significantly improved outcomes.

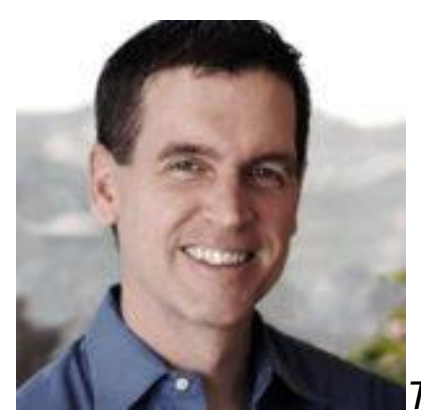

Thomas F. Osborne, MD, is Director of Medical Informatics at vRad (Virtual Radiologic), the leading teleradiology services and telemedicine company, which leverages its proprietary technology, data, and analytics capabilities to rapidly move patient images and information across a secure global network of 2,100 medical facilities in all 50 states.

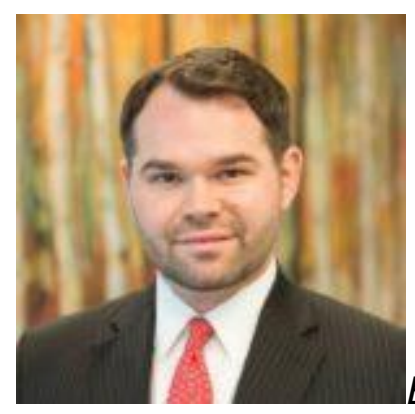

Bryan T. Arkwright, MHA, is Senior Consultant with Schumacher Clinical Partners, focusing on Telehealth/Telemedicine Strategy and Operations. 


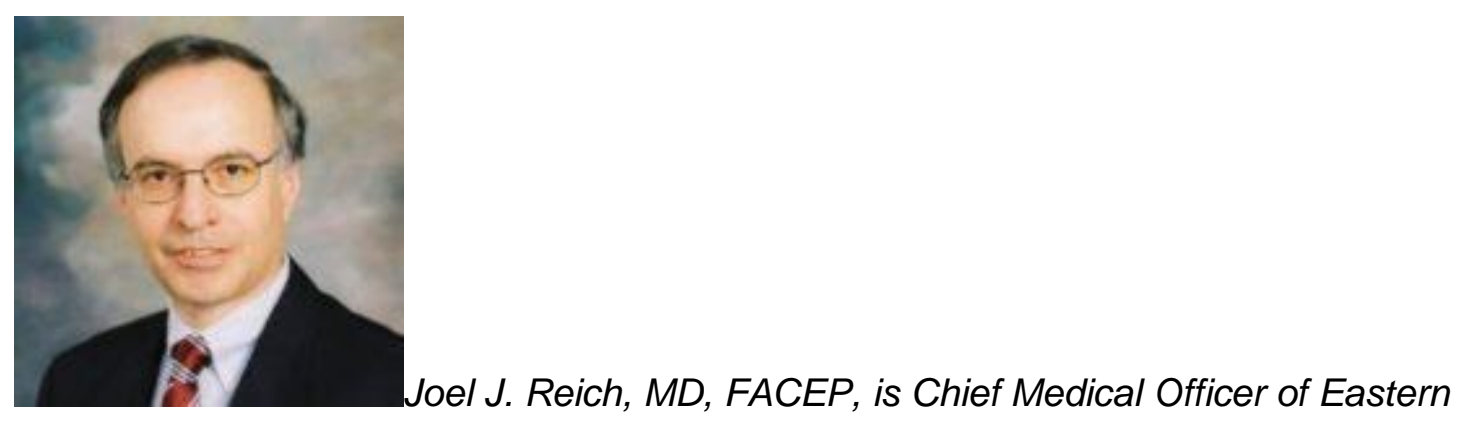

Connecticut Health Network.

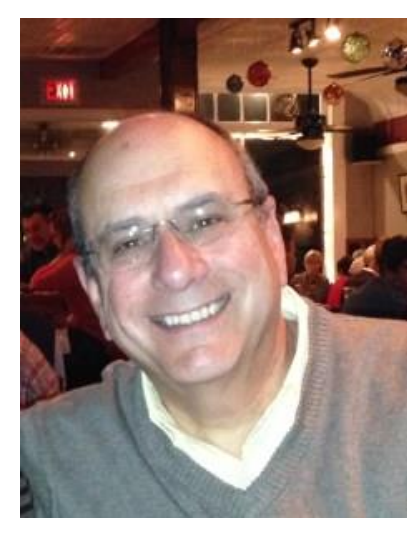

John Russo, Jr, PharmD, is Managing Editor of Telehealth and Medicine Today.

Dr. Osborne conceived the idea for this series of articles. He, Dr. Reich, and Mr. Arkwright contributed to the content. Dr. Russo provided editorial support.

\section{References}

1. Porter, R. (1999). The Greatest Benefit to Mankind: A Medical History of Humanity (The Norton History of Science). WW Norton \& Company.

2. Risse, G. B. (1999). Health care in hospitals: the past 1000 years. The Lancet, 354 , SIV25.

3. Porter, D. (Ed.). (1994). The History of Public Health and the Modern State (Vol. 26). Rodopi.

4. Ding, A. (2013). The History of Health Care in the United States Pre-1965. In: An Introduction to Health Policy (pp. 3-13). Springer New York. 
5. Abel, E. K. (1995). A "terrible and exhausting" struggle: family caregiving during the transformation of medicine. Journal of the History of Medicine and Allied Sciences, 50(4), 478-506.

6. Finzsch, N., \& Jütte, R. (2003). Institutions of Confinement: Hospitals, Asylums, and Prisons in Western Europe and North America, 1500-1950. Cambridge University Press.

7. Daschle, T., \& Dorsey, E. R. (2015). The return of the house call. Annals of Internal Medicine, 162(8), 587-588.

8. Goldfield, N. (2010). The evolution of diagnosis-related groups (DRGs): from its beginnings in case-mix and resource use theory, to its implementation for payment and now for its current utilization for quality within and outside the hospital. Quality Management in Healthcare, 19(1), 3-16.

9. O'Shaughnessy, C. V. (2013). The Basics: National Spending for Long-Term Services and Supports. 2012. Washington, DC: National Health Policy Forum, George Washington University. Available from: http://www.nhpf.org/library/thebasics/Basics LTSS 03-27-14.pdf.

10. Colello, K. J., Mulvey, J., \& Talaga, S. R. (2013, April). Long-term services and supports: Overview and financing. In Congressional Research Service Report for Congress. Available from:

http://digital.library.unt.edu/ark:/67531/metadc462393/m1/1/high res d/R42345 2013A pr04.pdf.

11. US Department of Health and Human Services. (2003). The future supply of long-term care workers in relation to the aging baby boom generation: Report to Congress. Washington DC: US DHHS. Available from: https://aspe.hhs.gov/pdfreport/future-supply-long-term-care-workers-relation-aging-baby-boom-generation".

12. Bipartisan Policy Center. America's long-term care crisis: Challenges in financing and delivery. 2014. Available from: http://bipartisanpolicy.org/wpcontent/uploads/2014/03/BPC-Long-Term-Care-Initiative.pdf

13. Reinhard, S. C., Kassner, E., Houser, A., \& Mollica, R. (2011). Raising expectations: A state scorecard on long-term services and supports for older adults, people with 
physical disabilities, and family caregivers. Washington, DC: AARP. Available from: http://www.longtermscorecard.org/.

14. U.S. Senate Commission on Long-Term Care. Report to the Congress. 2013. Available from: http://www.gpo.gov/fdsys/pkg/GPO-LTCCOMMISSION/pdf/GPOLTCCOMMISSION.pdf.

15. Takahashi, P. Y., Pecina, J. L., Upatising, B., Chaudhry, R., Shah, N. D., Van Houten, H., ... \& Hanson, G. J. (2012). A randomized controlled trial of telemonitoring in older adults with multiple health issues to prevent hospitalizations and emergency department visits. Archives of Internal Medicine, 172(10), 773-779.

16. White House Conference on Aging Staff. Long-term services and supports policy brief.," In: 2015 White House Conference on Aging. Washington, DC: U.S. Department of Health and Human Services. 2015.

17. Doty, P. (2010). The evolving balance of formal and informal, institutional and noninstitutional long-term care for older Americans: A thirty-year perspective. Public Policy \& Aging Report, 20(1), 3-9.

18. Wiener, J. M. (2013). After CLASS: The long-term care commission's search for a solution. Health Affairs, 32(5), 831-834.

19. Cusack, C. M., Pan, E., Hook, J. M., Vincent, A., Kaelber, D. C., \& Middleton, B. (2008). The value proposition in the widespread use of telehealth. Journal of Telemedicine and Telecare, 14(4), 167-168.

20. Harris-Kojetin, L., Sengupta, M., Park-Lee, E., Valverde, R., Caffrey, C., Rome, V., \& Lendon, J. (2016). Long-Term Care Providers and Services Users in the United States: Data From the National Study of Long-Term Care Providers, 2013-2014. Vital \& health statistics. Series 3, Analytical and epidemiological studies/[US Dept. of Health and Human Services, Public Health Service, National Center for Health Statistics], (38), 1 118.

21. Haupt, B. J., \& Jones, A. (1999). The National Home and Hospice Care Survey: 1996 summary. Vital and health statistics. Series 13, Data from the National Health Survey, (141), 1-238.

22. Gordy, S., \& Trunkey, D. (2014). Changing Demographics of the American Population. In Geriatric Trauma and Critical Care (pp. 3-9). Springer New York. 
23. Centers for Medicare and Medicaid Services. Chronic Condition Data Warehouse. West Des Moines, IA: Buccaneer, A General Dynamics Company; 2012. Chronic condition categories. (Available from: http://www.ccwdata.org/chronic-conditions/index.htm).

24. Elias, E. R., Murphy, N. A., Liptak, G. S., Adams, R. C., Burke, R., Friedman, S. L., ... \& Norwood, K. W. (2012). Home care of children and youth with complex health care needs and technology dependencies. Pediatrics, 129(5), 996-1005.

25. Hewitt-Taylor, J. (2012). Planning the transition of children with complex needs from hospital to home. Nursing Children and Young People, 24(10), 28.

26. Patel, S., Park, H., Bonato, P., Chan, L., \& Rodgers, M. (2012). A review of wearable sensors and systems with application in rehabilitation. Journal of Neuroengineering and Rehabilitation, 9(1), 1.

27. Baig, M. M., \& Gholamhosseini, H. (2013). Smart health monitoring systems: an overview of design and modeling. Journal of Medical Systems,37(2), 1-14.

28. Milenković, A., Otto, C., \& Jovanov, E. (2006). Wireless sensor networks for personal health monitoring: Issues and an implementation. Computer Communications, 29(13), 2521-2533.

29. Salive, M. E. (2013). Multimorbidity in older adults. Epidemiologic Reviews, mxs009.

30. Maher, R. L., Hanlon, J., \& Hajjar, E. R. (2014). Clinical consequences of polypharmacy in elderly. Expert Opinion on Drug Safety, 13(1), 57-65.

31. Scott, I. A., Hilmer, S. N., Reeve, E., Potter, K., Le Couteur, D., Rigby, D., .. \& Jansen, J. (2015). Reducing inappropriate polypharmacy: the process of deprescribing. JAMA Internal Medicine, 175(5), 827-834.

32. Bronskill, S. E., Gill, S. S., Paterson, J. M., Bell, C. M., Anderson, G. M., \& Rochon, P. A. (2012). Exploring variation in rates of polypharmacy across long term care homes. Journal of the American Medical Directors Association, 13(3), 309-e15.

33. Bao, Y., Shao, H., Bishop, T. F., Schackman, B. R., \& Bruce, M. L. (2012). Inappropriate medication in a national sample of US elderly patients receiving home health care. Journal of General Internal Medicine, 27(3), 304-310.

34. Kalisch, B. J., Tschannen, D., \& Lee, K. H. (2012). Missed nursing care, staffing, and patient falls. Journal of Nursing Care Quality, 27(1), 6-12. 
35. Hirsbrunner, T., Denhaerynck, K., Fierz, K., Milisen, K., \& Schwendimann, R. (2015). Nurse staffing, patient turnover and safety climate and their association with in-patient falls and injurious falls on medical acute care units: a cross-sectional study. Journal of Hospital Administration, 4(3), p54.

36. Dumanovsky, T., Rogers, M., Spragens, L. H., Morrison, R. S., \& Meier, D. E. (2015). Impact of Staffing on Access to Palliative Care in US Hospitals. Journal of Palliative Medicine, 18(12), 998-999.

37. Rimsza, M. E., Hotaling, A. J., Keown, M. E., Marcin, J. P., Moskowitz, W. B., Sigrest, T. D., \& Simon, H. K. (2015). The use of telemedicine to address access and physician workforce shortages. Pediatrics, 136(1), 202-209.

38. Osborne TF, Reich JJ, Arkwright MHA, Russo, Jr, J. On the digital road to home healthcare. Telehealth and Medicine Today. 2016 August 1(3). URL: http://www.telhealthandmedtoday.com/on-the-digital-road-to-improved-homehealthcare/. Accessed 9/20/16.

39. Berwick DM, Nolan TW, Whittington J. The Triple Aim: Care, health, and cost. Health Affairs. 2008;27(3):759-769. doi:10.1377/hlthaff.27.3.759.

40. Case J. A Primer on defining the Triple Aim. Blog by Jameson Case. Friday, October 17, 2014. URL:

http://www.ihi.org/communities/blogs/ layouts/ihi/community/blog/itemview.aspx? List=8 1ca4a47-4ccd-4e9e-89d9-14d88ec59e8d\&ID=63. Accessed July 27, 2016.

41. Accenture. Tech-savvy seniors want online options to access care from home, Accenture survey shows.URL: https://newsroom.accenture.com/industries/health-publicservice/tech-savvy-seniors-want-online-options-to-access-care-from-home-accenturesurvey-shows.htm. Accessed August 5, 2016.

42. National Institute on Aging. There's no place like home-for growing old. URL: https://www.nia.nih.gov/health/publication/theres-no-place-home-growing-old. Accessed August 5, 2016.

43. Family Caregiver Alliance. Selected long-term care statistics. 2015. URL: https://www.caregiver.org/selected-long-term-care-statistics Accessed August 11, 2016. 44. Viers BR, Pruthi S, Rivera ME, et al. Are patients willing to engage in telemedicine for their care: A survey of preuse perceptions and acceptance of remote video visits in a 
urological patient population. Urology. 2015;85(6):1233-1240.

doi:10.1016/j.urology.2014.12.064.

45. NORC at the University of Chicago. Health IT and health disparities: Patient provider telehealth network-using telehealth to improve chronic disease management. 2012. URL: https://www.healthit.gov/sites/default/files/pdf/RCCHCandPHS CaseStudy.pdf. Accessed July 10, 2016.

46. Broderick A, Lindeman D. Case studies in telehealth adoption. The Commonwealth Fund; 2013. URL:

http://www.commonwealthfund.org/ /media/Files/Publications/Case\%20Study/2013/Jan /1654 Broderick telehealth adoption synthesis.pdf. Accessed July 10, 2016.

47. Chau PYK, Hu PJH. Investigating healthcare professionals' decisions to accept telemedicine technology: an empirical test of competing theories. Inform Manage. 2000;39:297-311.

48. Singh R, Mathiassen L, Stachura ME, Astapova EV. Dynamic capabilities in home health: IT-enabled transformation of post-acute care. JAMIA. 2011;12:163-188.

49. Murias G, Sales B, Garcia-Esquirol O, Blanch L. Telemedicine in critical care. Open Respir Med J. 2009 Mar 12;3:10-6. doi: 10.2174/1874306400903010010.

50. Jimison H, Gorman P, Woods S, et al. Barriers and drivers of health information technology use by the elderly chronically ill and underserved. AHRQ Publication No. 09E004. 2008. URL:

http://www.ahrq.gov/downloads/pub/evidence/pdf/hitbarriers/hitbar.pdf. Accessed July 10, 2016.

51. Munro D. Targeting the 'superusers' of healthcare with telehealth. Forbes. May 2015. http://www.forbes.com/sites/danmunro/2015/05/03/targeting-the-superusers-ofhealthcare-with-telehealth/\#3296cb6d5dd3. Accessed August 5, 2016.

52. Denesen B, Nonnecke B, Lindeman D, et al. Personalized health in the future: A global research agenda. J Med Internet Res. 2016;18(3):e53.

53. Ekeland AG, Bowes A, Flottorp S. Effectiveness of telemedicine: a systematic review of reviews. Int J Med Inform. 2010;79(11):736-771. 
54. Mushcab H, Kernohan WG, Wallace J, Martin S. Web-based remote monitoring systems for self-managing type 2 diabetes: A systematic review. Diabetes Technol Ther. 2015;17(7):498-509.

55. Dahl D, Reisetter JA, Zismann N. People, technology, and process meet the Triple Aim. Nurs Admin Q. 2014;38(1):13-21.

56. Maeng DD, Starr AE, Tomcavage JF, Sciandra J, Salek D, Griffith D. Popul Health Manag. 2014;17(6):340-344.

57. Frakt AB, Mayes R. Beyond capitation: How new payment experiments seek to find the 'sweet spot' in amount of risk providers and payers bear. Health Affairs. 2012;31(9):1951-1958. doi:10.1377/hlthaff.2012.0344.

58. Leff B, Carlson CM, Saliba D, Ritchie C. The invisible homebound: Setting quality-ofcare standards for home-bound primary and palliative care. Health Aff. 2014;34(1):2129.

59. Nguyen OK, Makam AN, Clark C, et al. Vital signs are still vital: Instability on discharge and the risk of post-discharge adverse outcomes. J Gen Intern Med. August 2016. doi:10.1007/s11606-016-3826-8.

60. Silow-Carroll S, Edwards JN, Lashbrook A. Reducing hospital readmissions: Lessons from top-performing hospitals. The Commonwealth Fund. 2011 April 6th. URL: http://www.commonwealthfund.org/publications/case-studies/2011/apr/reducinghospital-readmissions. Accessed 9/20/16.

61. Davis C, Bender M, Smith T, Broad J. Feasibility and acute care utilization outcomes of a post-acute transitional telemonitoring program for underserved chronic disease patients. Telemed J E Health. 2015;21(9):705-713.

62. Wade, V. A., Karnon, J., Elshaug, A. G., \& Hiller, J. E. (2010). A systematic review of economic analyses of telehealth services using real time video communication. BMC health services research, 10(1), 1.

63. Liker, J. K. (2004). The Toyota Way. McGraw-Hill Education.

64. Collins, J. C. (2001). Good to Great: Why Some Companies Make the Leap... and Others Don't. Random House.

65.Ploeg, J., Davies, B., Edwards, N., Gifford, W., \& Miller, P. E. (2007). Factors Influencing Best-Practice Guideline Implementation: Lessons Learned from 
Administrators, Nursing Staff, and Project Leaders. Worldviews on Evidence-Based Nursing, 4(4), 210-219.

66. Kearns, G. S., \& Sabherwal, R. (2006). Strategic alignment between business and information technology: a knowledge-based view of behaviors, outcome, and consequences. Journal of Management Information Systems,23(3), 129-162.

67. Koch, S. (2006). Home telehealth—current state and future trends. International Journal of Medical Informatics, 75(8), 565-576.

68. Finkbeiner, M., Schau, E. M., Lehmann, A., \& Traverso, M. (2010). Towards life cycle sustainability assessment. Sustainability, 2(10), 3309-3322.

69. Wheelwright, S. C., \& Clark, K. B. (1992). Creating project plans to focus product development. Harvard Business School Pub.

70. Cimperman, M., Brenčič, M. M., Trkman, P., \& Stanonik, M. D. L. (2013). Older adults' perceptions of home telehealth services. Telemedicine and e-Health, 19(10), 786-790.

71. US Department of Health and Human Services, \& US Department of Health and Human Services. (2010). The registered nurse population: Findings from the 2008 national sample survey of registered nurses. Health Resources and Services Administration, (ed.). US Department of Health and Human Services.

72. Lake, E. T., \& Friese, C. R. (2006). Variations in nursing practice environments: relation to staffing and hospital characteristics. Nursing Research, 55(1), 1-9.

73. Flynn, L., Dickson, G., \& Moles, D. J. (2007). Focus on caregiving. Enhancing the nursing workplace: In a recent study of long term care nurses, key organizational factors emerge as most important in supporting a productive work environment. Provider, 33(1), 35-9.

74. Perrin, A., \& Duggan, M. (2015). Americans' internet access: 2000-2015.Pew Research Center, 26. Available from http://www.pewinternet.org/2015/06/26/americans-internetaccess-2000-2015. 2015

75. Gindi, R. M., Zipf, G., Galinsky, A. M., Miller, I. M., Nwankwo, T., \& Terry, A. L. (2014). Comparison of in-home collection of physical measurements and biospecimens with collection in a standardized setting: the health measures at home study. Vital and health statistics. Series 2, Data evaluation and methods research, (164), 1-16. 
76. Wilkowska, W., \& Ziefle, M. (2012). Privacy and data security in E-health: Requirements from the user's perspective. Health Informatics Journal, 18(3), 191-201.

77. Luxton, D. D., Kayl, R. A., \& Mishkind, M. C. (2012). mHealth data security: The need for HIPAA-compliant standardization. Telemedicine and e-Health,18(4), 284-288.

78. Kotz, D., Gunter, C. A., Kumar, S., \& Weiner, J. P. (2016). Privacy and Security in Mobile Health: A Research Agenda. Computer, 49(6), 22-30.

79. Fleming, N. S., Becker, E. R., Culler, S. D., Cheng, D., McCorkle, R., Graca, B. D., \& Ballard, D. J. (2014). The impact of electronic health records on workflow and financial measures in primary care practices. Health Services Research, 49(1pt2), 405-420.

80. Page, C. A. K., \& Schadler, A. (2014). A nursing focus on EMR usability enhancing documentation of patient outcomes. Nursing Clinics of North America, 49(1), 81-90.

\section{Tags}

cost of care, home telehealth, how does telehealth enhance the doctor patient relationship, individual experience of care, providing value, spectrum of home health patients, telehealth and telemedicine, telemedicine process improvement, telemedicine program implementation, telemedicine remote health, Triple Aim, what is telemedicine and how does it work, 